\title{
THE EFFECTS OF ETOMIDATE ON ARTERIAL PRESSURE, PULSE RATE AND PREGANGLIONIC SYMPATHETIC ACTIVITY IN CATS
}

\author{
Per Skovsted ${ }^{\circ}$ and Sanguan Sapthavichaukul $\dagger$
}

EтоміDATE is a new short-acting non-barbiturate intravenous anaesthetic. It is water soluble and rapidly metabolized in the liver. ${ }^{1}$ It has some cardiovascular actions similar to those found with short acting barbiturates, ${ }^{2}$ althesin ${ }^{3}$ and propanidid ${ }^{4}$ in that it produces hypotension and tachycardia, but apparently to a lesser degree. ${ }^{5}$ Since no study has been made on the effect of etomidate on sympathetic nervous activity, we have done a study using the same technique as was used in the study of the other intravenous anaesthetics mentioned above.

\section{Method and Material}

Ten cats were used in the experiment. They were studied under a basal anaesthesia of 50 per cent nitrous oxide in oxygen with decamethonium used for muscle relaxation. Respiration was controlled with a respirator. End-tidal carbon dioxide was measured by a capnograph and kept at constant level. Metabolic acidosis, if occurring, was corrected with intravenous sodium bicarbonate. Detailed description of the surgical preparation has been reported elsewhere. ${ }^{2}$

Sympathetic nervous activity was measured from teased strands of the left cervical sympathetic trunk. Arterial pressure was measured from a canula in a femoral artery. The following parameters were recorded on a Grass Polygraph: Arterial pressure, mean arterial pressure, end-tidal carbon dioxide, sympathetic nervous activity in impulses per second (imps/sec), and pulse rate measured by a tachograph triggered by the pulse wave.

Five animals were studied in a normal state with only the cervical sympathetic trunk sectioned. Five animals were studied in a baroreceptor-denervated state with all barostatic nerves and both vagi surgically sectioned.

Etomidate was administered as a bolus injection of $0.8 \mathrm{mg} / \mathrm{kg}$, a dose selected in a few pilot studies as sufficient to produce a moderate decline in arterial pressure. Information about anaesthetic doses for etomidate required in cats were unavailable at the time of the study.

\footnotetext{
"Per Skovsted, M.D., Anaesthetist in Chief, Rigshospitalet.

†Sanguan Sapthavichaikul, M.D., Senior Instructor of Anaesthesia.

Department of Anaesthesiology, Hahnemann Medical College and Hospital of Philadelphia, Pennsylvania, 19102, U.S.A., and Department of Anaesthesia, Rigshospitalet (State University Hospital), Blegdamsvej 9, 2100 Copenhagen, Denmark.

Supported in part by NIH Grant H.L. 15392-03.
} 


\section{EFFECTS OF ETOMIDATE ON SYMPATHETIC NERVOUS ACTIVITY ARTERIAL PRESSURE AND PULSE RATE IN CATS.}
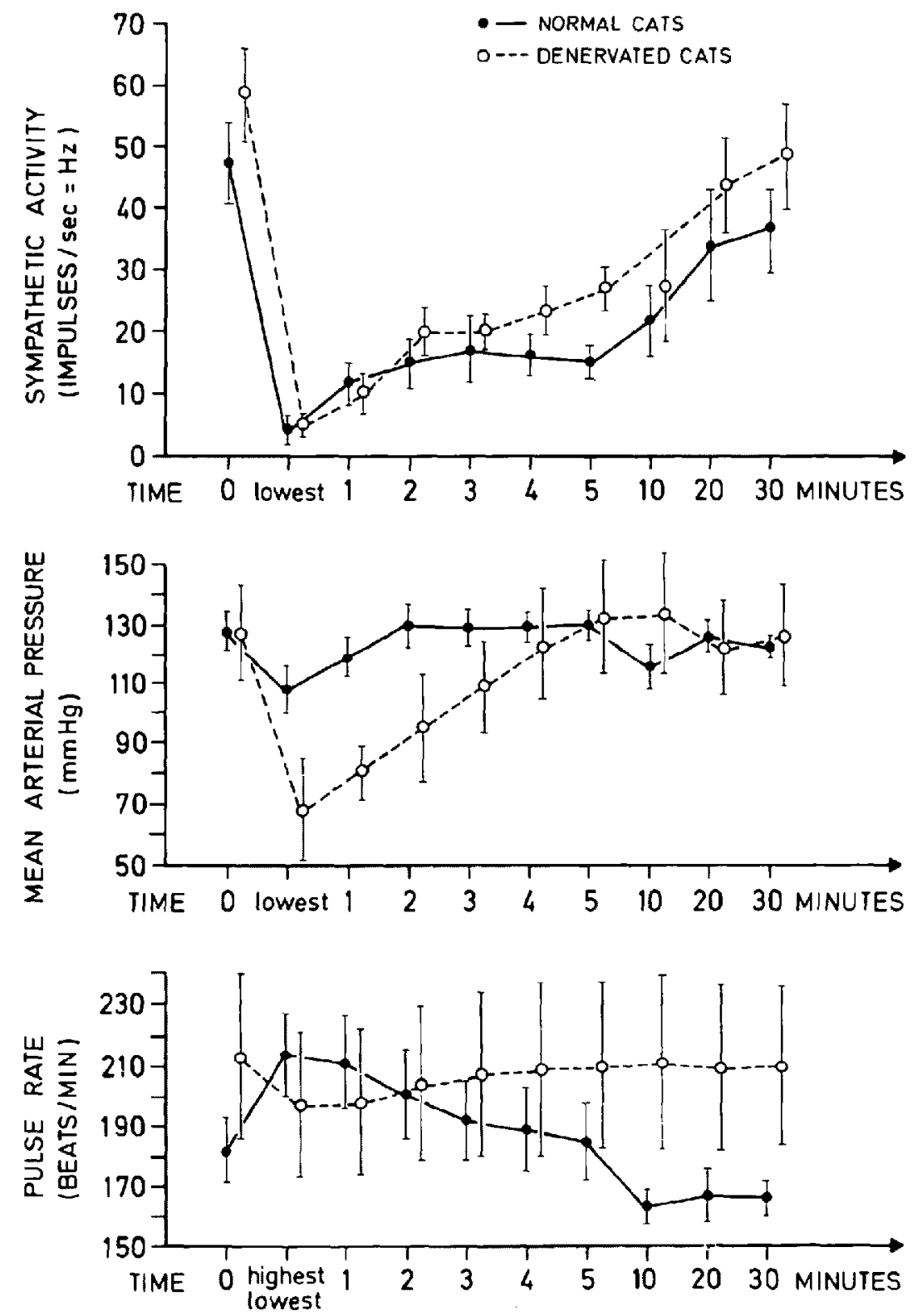

Ficure 1. Effects of etomidate on sympathetic nervous activity, mean arterial pressure, and pulse rate in nomal and baroreceptor-denervated cats (Table $I$ in graphic form). High and low values were invariably reached within the first minute after injection of etomidate. 


\section{Normal Animals}

\section{RESULTS}

The response of sympathetic nervous activity, mean arterial pressure, and pulse rate to etomidate is shown in Figures 1 and 2, and in Table I. After injection of etomidate in normal animals a marked decline was noted in sympathetic activity from $48 \pm 7$ to $4 \pm 2$ imps/ $/ \mathrm{sec}(p<0.01)$. It took 20 minutes for sympathetic activity to return to a level not significantly different from the initial level. Mean arterial blood pressure declined from $128 \pm 7$ to $108 \pm 8$ torr $(\mathrm{p}<0.05$ ), but returned to the initial level within one minute in spite of a markedly depressed sympathetic tone.

Pulse rate increased from $182 \pm 11$ to $214 \pm 14$ beats per minute $(p<0.05)$, but returned to the initial level within two minutes.

\section{Denervated Animals}

The response in sympathetic tone evoked by etomidate in denervated animals was similar to that found in normal animals. Sympathetic tone declined from $59 \pm 8 \mathrm{imps} / \mathrm{sec}$ to $5 \pm 2 \mathrm{imps} / \mathrm{sec}$ and recovered in 20 minutes. Mean arterial pressure fell significantly more than was observed in normal animals from $1.27 \pm 16$ to $67 \pm 17$ torr $(p<0.01)$. Based on a percentage level denervated animals also showed a significantly greater depression in arterial pressure than was seen in normal animals $-62 \pm 6$ per cent of initial level versus $84 \pm 5$ per cent $-(\mathrm{p}<0.05)$. Denervated animals also showed a brief bradycardia $213 \pm 27$ to $197 \pm 24$ beats per minute $(p<0.02)$ lasting for 2 minutes instead of the tachycardia noted in normal animals. The results are listed in Table I and Figure 2.

\section{Discussion}

Etomidate in the dosage used $(0.8 \mathrm{mg} / \mathrm{kg})$ has been shown to cause a marked and long-lasting depression of sympathetic activity almost unreflected by changes in arterial pressure. Since the mild tachycardia noted in normal animals can only in part have counteracted the depression in arterial pressure expected from the severely depressed sympathetic tone, it appears likely that the direct cardiovascular depressant action of etomidate is minimal. When baroreceptor-denervated animals responded to etomidate with bradycardia instead of tachycardia it might be due in part to the depressed sympathetic tone and in part to a direct negative chrontropic effect of etomidate which deserves further studies.

The slow return of sympathetic tone appears somewhat in contrast to the postulated fast metabolism of the drug, ${ }^{1}$ but this might be explained in part on the basis of the dosage of the drug used.

The tachycardia seen in normal animals in spite of depressed sympathetic tone, on the other hand, especially when related to the findings in denervated animals, can only be explained on the basis of a vagolytic action of etomidate.

\section{SUMMARY}

We have studied the effects of etomidate on preganglionic cervical sympathetic activity, arterial pressure, and pulse rate. 


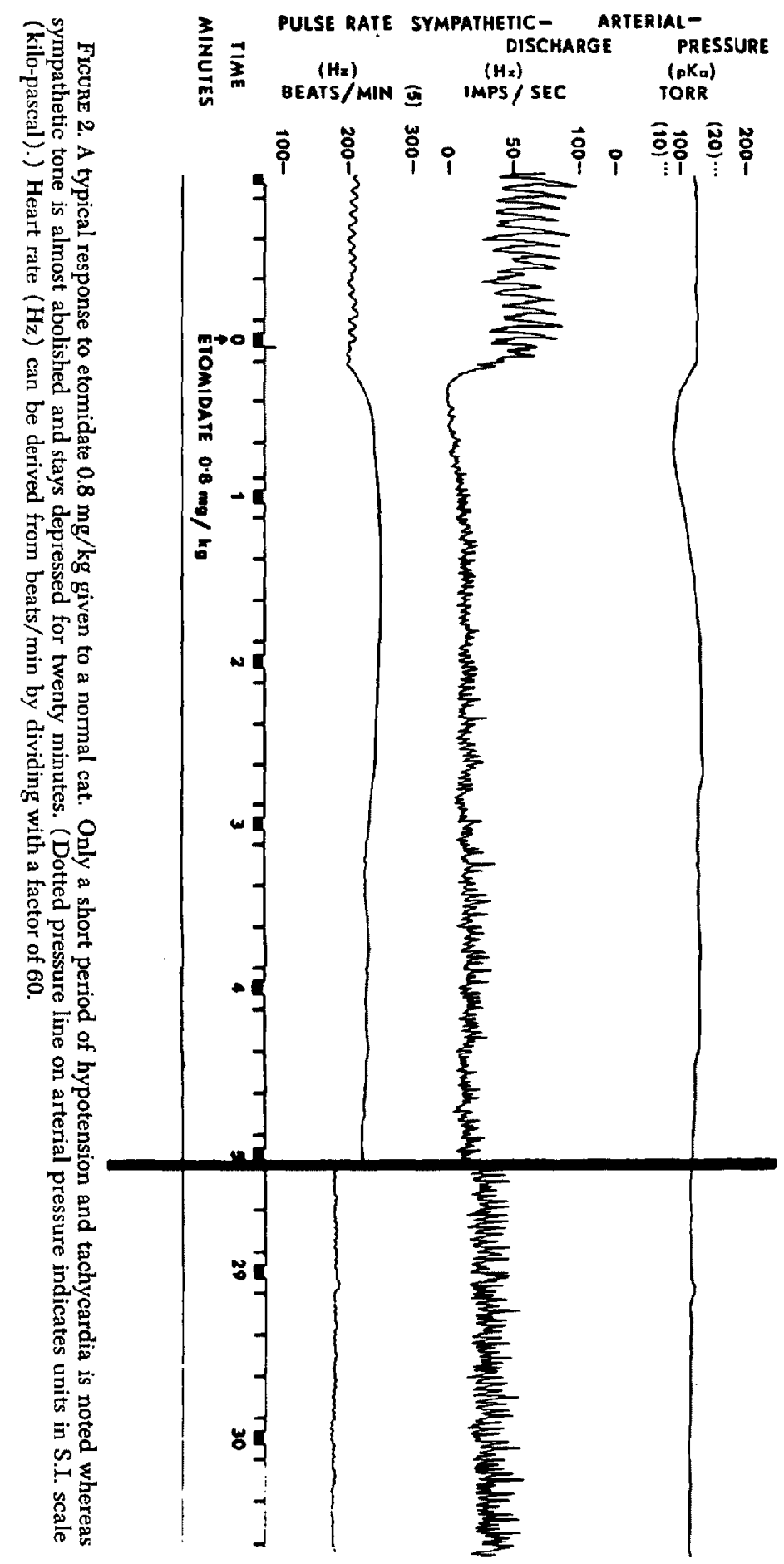




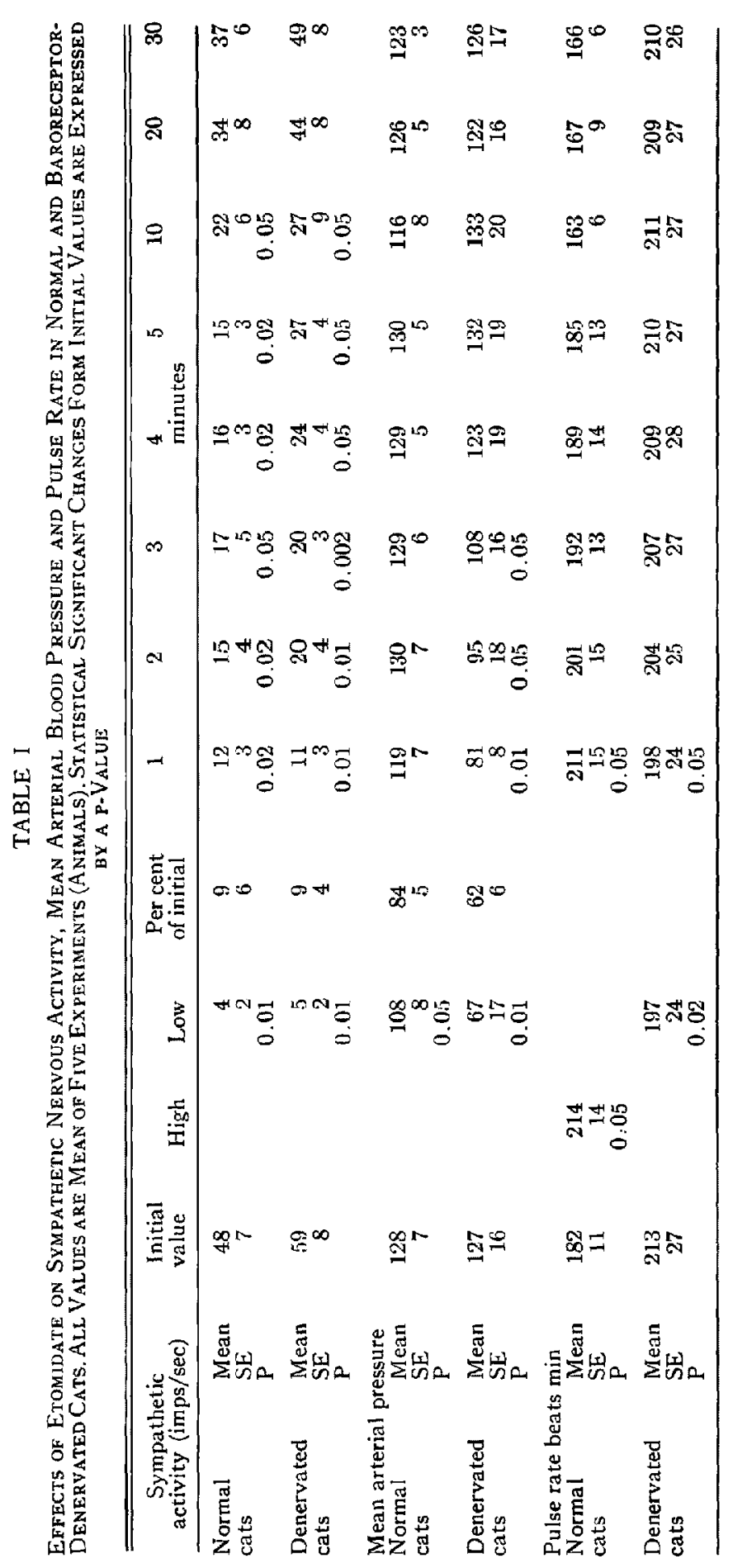


Normal and baroreceptor-denervated animals were studied. On the basis of findings it is concluded that etomidate exerts a minimal direct depressant action on the cardiovascular system. A profound depression of sympathetic tone was observed in spite of unaffected arterial pressure. Etomidate was also shown to possess a mild vagolytic action.

\section{RÉSUMÉ}

Nous avons étudié les effets de l'etomidate sur l'activité sympathique préganglionnaire cervicale, sur la pression artérielle et sur la fréquence cardiaque du chat. Cinq animaux normaux et cinq autres animaux en état de dénervation basoréceptrice ont été étudiés.

Nos résultats indiquent que l'etomidate exerce une action dépressive directe minime sur le système cardiovasculaire. On a cependant observé une dépression profonde du système sympathique même si la tension artérielle n'était pas modifiée. Nous avons également mis en évidence une action vagolytique légère de l'etomidate.

\section{ACKNOWLEDGEMENTS}

The authors would like to acknowledge the assistance of Dr. Henry L. Price, M.D., Research Director of the Department, Mr. Leo Davidson for his able technical assistance, Jonathan Korshin, M.D., for his assistance in preparation of the manuscript, and Kaj Wisborg, M.D., who participated in a few early experiments.

\section{REFERENCES}

1. $\mathrm{KAY}, \mathrm{B}$. A dose-response relationship for etomidate with some observations on cumulation, Br. J. Anaesth. 48: 213 (1976).

2. Skovsred, P., Price, M.L., \& Price, H.L. The effects of short-acting barbiturintes on arterial pressure, preganglionic sympathetic activity and barostatic reflexes. Anesthesiology 33: $10(1970)$.

3. Saptiavichaikul, S., Wishong, K., \& Skovsted, P. The effects of althesin on arterial pressure, pulse rate, preganglionic sympathetic activity and barostatic reflexes in cats. Canad. Anaesth. Soc. J. 22: 587 (1975).

4. Wisborci, K., Sapthavichaikul, S., \& Skovsted, P. The effects of propanidid on arterial pressure, pulse rate, preganglionic sympathetic activity and barostatic reflexes in the cat. Canad. Anaesth. Soc. J. 24: 505 (1977).

5. Rifat, K., Gaiulis, Z., \& Gesperle, M. Etomidate: effects cardiovasculaires du nouvel agent anesthesique intraveineux. Canad. Anaesth. Soc. J. 23: 492 (1976). 